\title{
Some structural design issues of the 14-storey timber framed building "Treet" in Norway
}

\author{
K. A. Malo ${ }^{1}$ R. B. Abrahamsen ${ }^{2}$ M. A. Bjertnæs ${ }^{2}$
}

Received: 16 February 2015/Published online: 18 March 2016

(c) The Author(s) 2016. This article is published with open access at Springerlink.com

\begin{abstract}
Treet" is a 14-storey timber apartment building in Norway currently under construction. Ground works started in April 2014, and the residents can move in autumn of 2015. The building will be one of the tallest timber buildings in the world. The building consists of load-carrying glulam trusses and two intermediate strengthened levels. Prefabricated building modules are stacked on top of the concrete garage and on top of the strengthened levels. There is CLT in the elevator shaft, internal walls and balconies. But, CLT is not a part of the main load bearing system. Glass and metal sheeting protect the structural timber from rain and sun. The paper presents the design of the building as well as many of the investigations, considerations and discussions which took place during the design process. Finally some of the design verifications are presented.
\end{abstract}

\section{Introduction}

The fourteen storey residential building "Treet" is located in the city of Bergen, Norway. "Treet" means "The tree" in Norwegian. The design process started in 2011 and was finalized in 2013. The first ground works took place in April 2014, and the building will be finished in autumn 2015. At present, the building seems to become the tallest

K. A. Malo

kjell.malo@ntnu.no

1 Department of Structural Engineering, Norwegian University of Science and Technology, NTNU, Richard Birkelandsvei 1a, 7491 Trondheim, Norway

2 Structural engineering, Sweco Norway, Fåberggata 155, 2615 Lillehammer, Norway in the world of its kind. 62 apartments will find their new owners in the building visualized in Fig. 1.

The building has a net area of $5830 \mathrm{~m}^{2}$. The basement, which holds parking facilities, technical rooms and storage rooms, has a net area of $920 \mathrm{~m}^{2}$. There is a gym on the 9 th floor and a roof terrace at disposal for the residents.

The building site is in an urban and central area of Bergen. Bergen is the second largest city in Norway, and is located on the west coast of the country.

\section{Design}

\subsection{Structural system and floor plans}

The idea of the structural design concept may be explained by an analogy to a cabinet rack filled with drawers (Abrahamsen and Malo 2014). Here, the cabinet rack is formed by large glulam trusses, and the drawers consist of prefabricated residential modules. The glulam truss work has close resemblance to the design concepts used in modern timber bridge structures.

The glulam trusses along the façades give the building its necessary stiffness. The CLT elements are lightly supported by the load bearing structure, but the CLT structure have insignificant contribution to the global stiffness of the overall building. The CLT walls are hence almost independent of the main load bearing system, and do not show high stresses for horizontal loading.

Prefabricated building modules comprise the main volume of the building. The modules are stacked up to four storeys, and are found on levels 1-4, 5, 6-9, 10 and 11-14, confer Figs. 2 and 3. The ground floor is denoted level 1.

Levels 1-4 rest on the deck of a concrete garage. Level 5 (on the 4th floor) is a strengthened glulam storey connected 


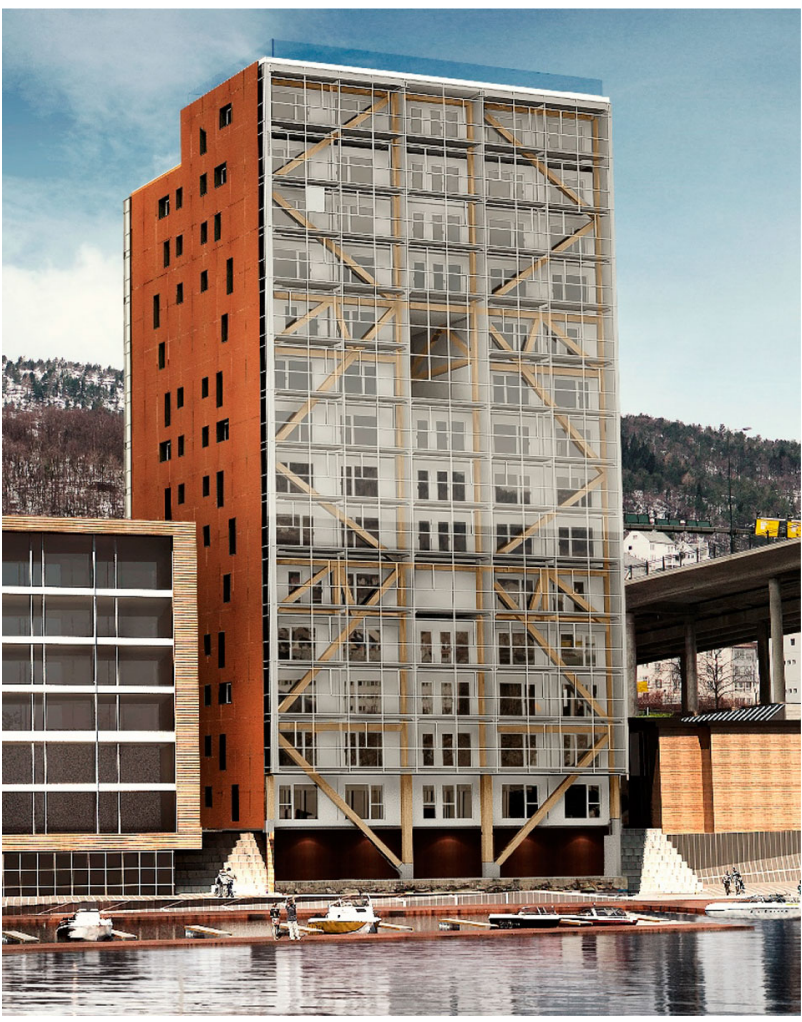

Fig. 1 "Treet". 3D-view from the south

to the façade trusses, denoted "power storey". The special modules on level 5 are connected to the glulam structure and do not rest on the building modules below. The "power storey" carries a prefabricated concrete slab on top, which acts as a base for the next four levels of stacked modules (6-9), just like levels 1-4. This building method and assembly are visualised in Fig. 7 through Fig. 10.

The modules on levels 6-9 do not connect to the main load bearing structure at any other point than at their foundation, which is the concrete slab. Then the system repeats itself with an additional "power storey" (level 10) and modules on top of that again (levels 11-14). The roof is also a prefabricated and element-based concrete slab. The concrete slabs are incorporated to connect the trusses, but an additional main function is to increase the mass of the building and hence to improve the dynamic behaviour, for more see Bjertnæs and Malo (2014).

Figure 4 shows a typical plan of the building. The $\mathrm{U}$-shape was chosen mainly for aesthetical reasons. Note the different module types; $\mathrm{A}$ and $\mathrm{B}$ are $4 \mathrm{~m} \times 8.7 \mathrm{~m}$ and module type $\mathrm{C}$ is $5.3 \mathrm{~m} \times 8.7 \mathrm{~m}$.

\subsection{Structural detailing}

The base of the building is a rectangle with length of baselines equal to $23 \times 21 \mathrm{~m}$. The height of the building is about $45 \mathrm{~m}$, confer Fig. 3. The maximum vertical distance

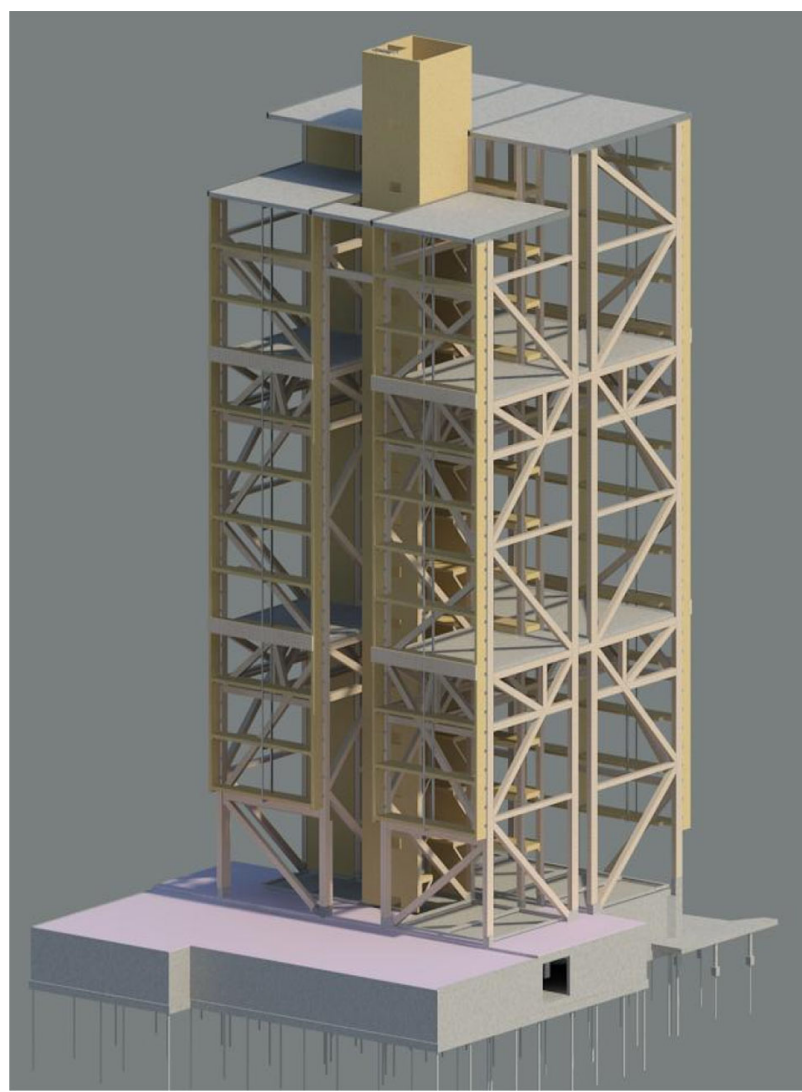

Fig. 23 D view of structural model showing also the concrete slabs on top of the "power storeys"

between the lowest and highest points of the timber components is about $49 \mathrm{~m}$.

Typical column cross-sectional dimensions are $405 \times 650$ and $495 \times 495 \mathrm{~mm}^{2}$, and typical diagonal cross-section is $405 \times 405 \mathrm{~mm}$.

All glulam elements are connected by use of slotted-in steel plates and dowels. This is a high capacity connection commonly used in bridges and large buildings in Norway. Typically, 3 steel plates of $8 \mathrm{~mm}$ thickness and various numbers of $12 \mathrm{~mm}$ dowels are used on "Treet"; see the side view drawing in Fig. 5 and a cross-section in Fig. 6. Figure 5 also shows the splicing of the vertical columns. Note that in order to fulfil the tolerance requirements, mounting gaps are introduced between the column elements. The gaps are filled with a high strength expanding acrylic mortar after installation. In general, the three steelplates are located in $10 \mathrm{~mm}$ wide slots located centrically in the cross section with in-between distance of $80 \mathrm{~mm}$. The length of the dowels is with few exceptions $275 \mathrm{~mm}$, and hence they do not extend to the glulam surface, confer Fig. 6. Both the engineers of the project as well as the glulam manufacturer have confidence in and experience with this type of connections, so other connection designs were not discussed. 


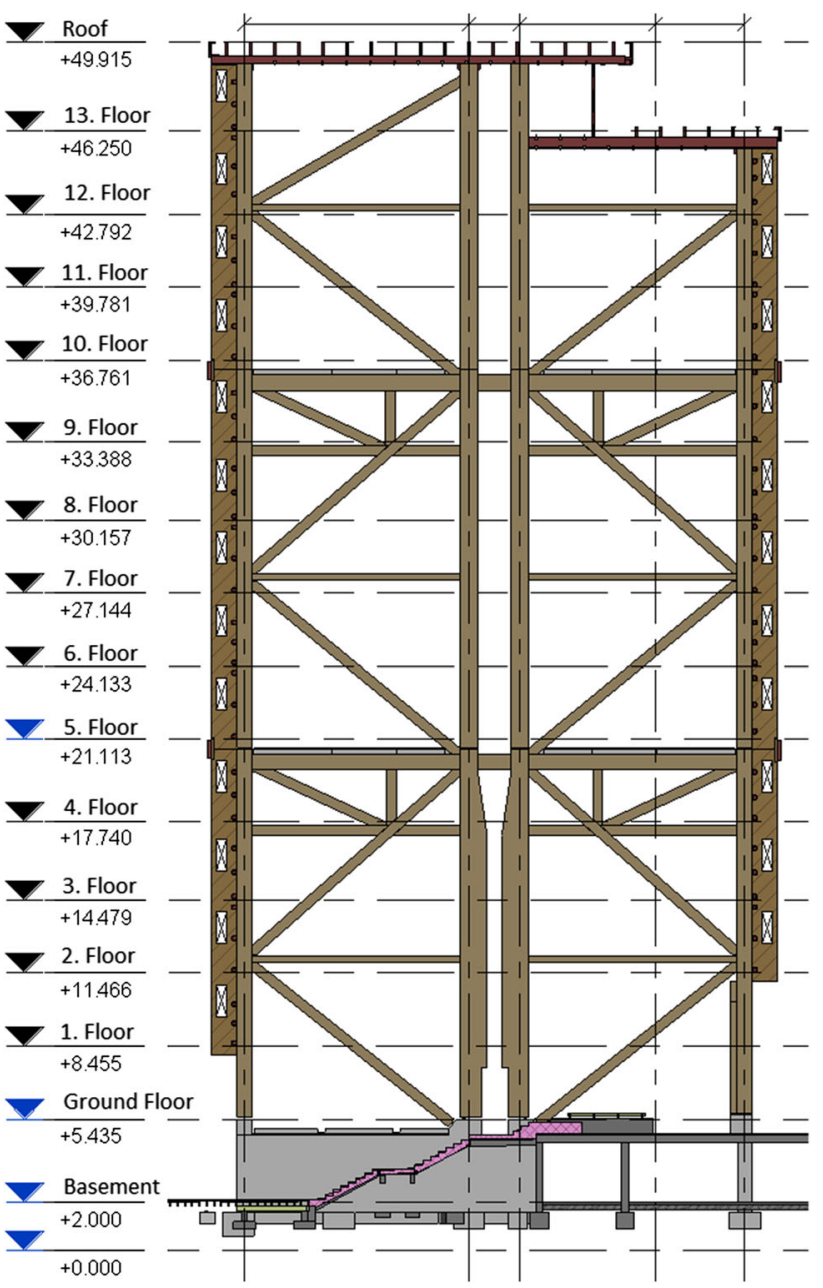

Fig. 3 Vertical section of load bearing structure

The bedrock is about $5 \mathrm{~m}$ below the garage floor. More than 100 vertical and tilted steel core piles are driven into the bedrock acting as a foundation for the building. Some of the piles must also handle tension forces. When the building is exposed to wind loading, some of the diagonals and columns can get tensile forces. These forces are transferred to the ground by anchoring the glulam columns to the concrete foundation by the use of joints based on slotted-in steel plates and dowels as shown in Fig. 6.

The structure is given a robust design. In case of a failing member the building will not collapse, for example the load bearing structure for the corridor can also handle the additional load from an impact due to an overlying corridor falling down. The removal of a truss member will lead to other members taking more force, and this scenario was verified in the accidental limit state.

There is a theoretical clearance of $34 \mathrm{~mm}$ between building modules and glulam trusses. This is enough to ensure the necessary building tolerances, and to avoid that possible horizontal movement of modules and trusses

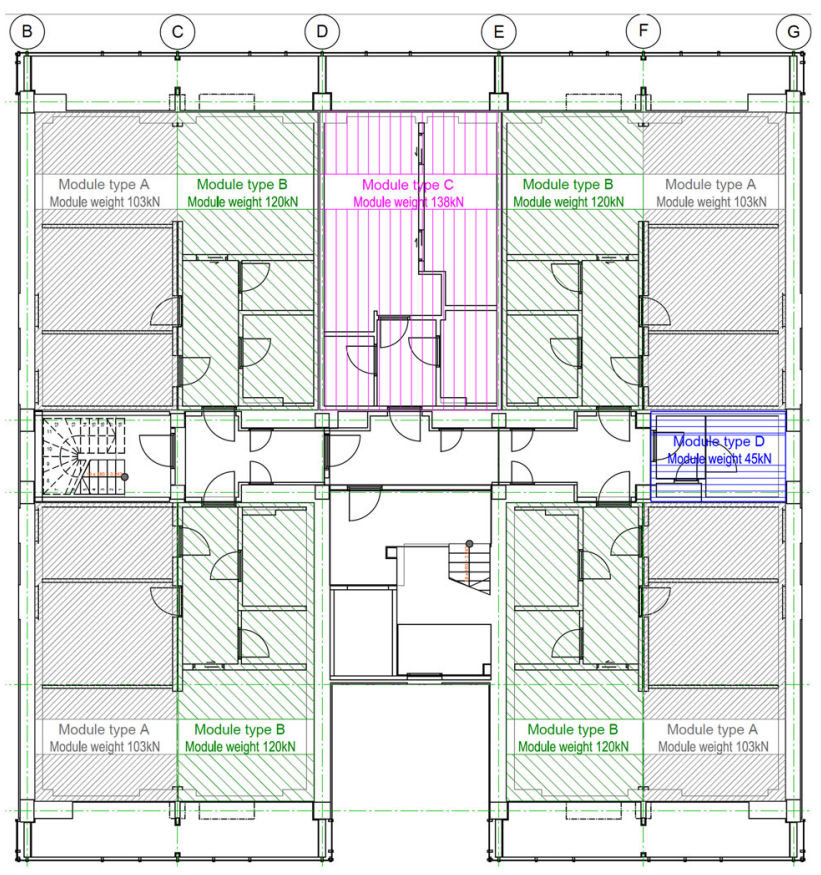

Fig. 4 Typical plan of building

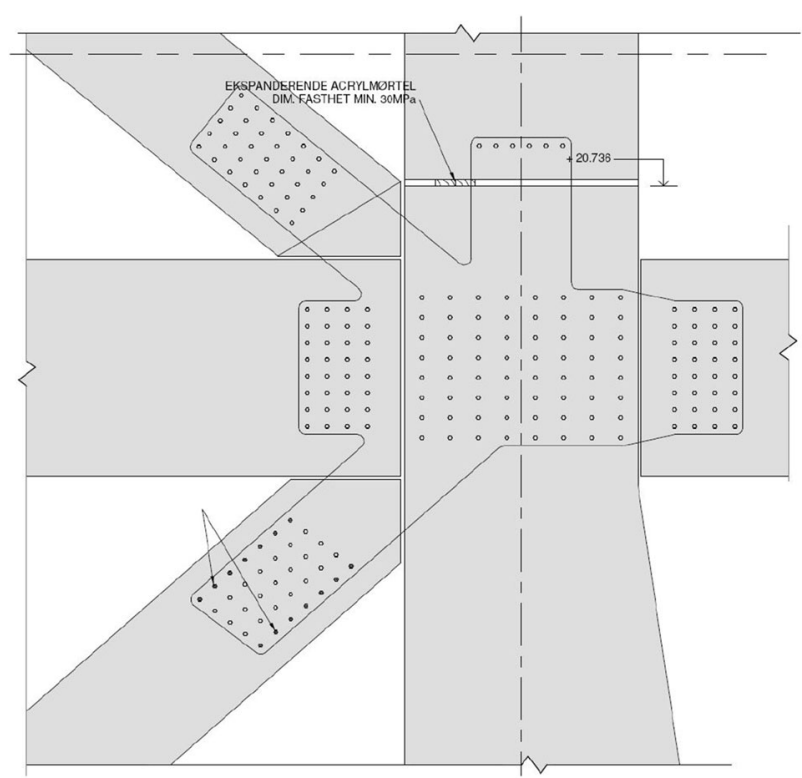

Fig. 5 Side view of connection with slotted-in steel plates and dowels

develop interface forces. The modules are stacked into the interior of the building in an ordinary way, placing the body sills on prepared small concrete foundation walls. The modules are not fastened in any other way than by contact stresses due to the deadweight. The modules can only be loaded laterally during erection, and this load case was evaluated by introducing frictional forces at the foundation as well as in between the modules. 


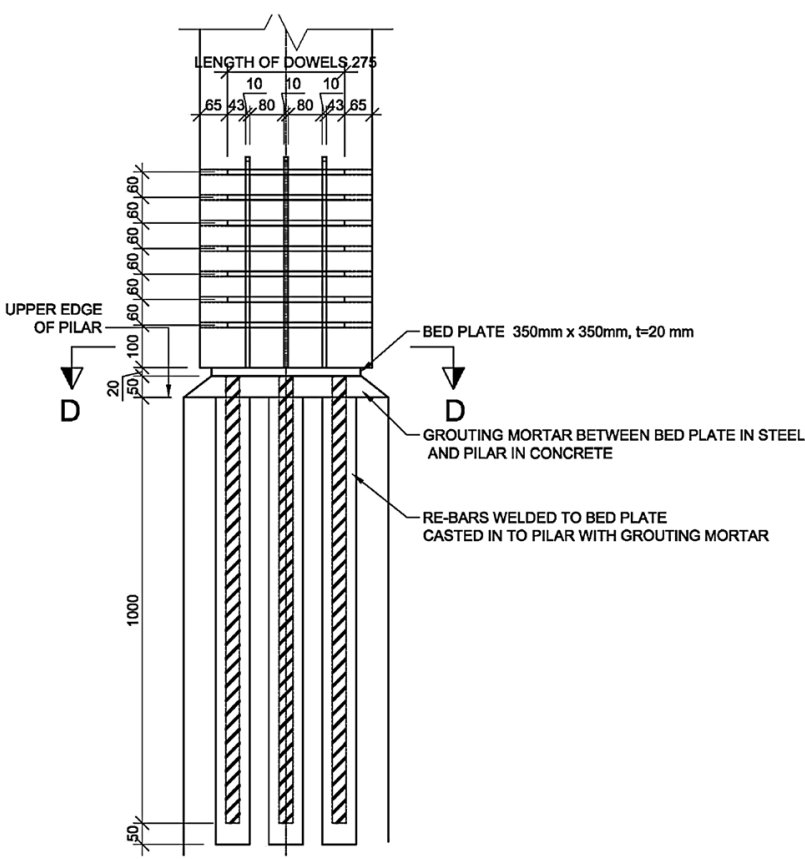

Fig. 6 Cross-section, anchoring of glulam to concrete

The external cladding and glazing of the building are attached to the load bearing trusses and to the balconies. The wind load will not affect the residential modules directly, except during the erection phase.

The structural timber is with few exceptions covered behind either glass or metal sheeting. This protects the timber from rain and sun, increases durability and reduces maintenance. Climate class 1 (service class 1) is used for members that are indoors, and climate class 2 is used for members that are on the cold side of the external walls.

\subsection{Materials}

All main load-bearing structures in "Treet" are wooden; glulam is used for the trusses, and cross-laminated timber (CLT) is used for the elevator shafts, staircases and internal walls. Timber framework is used in the building modules.

In the structural model, the properties stated for glulam strength classes GL30c and GL30 h according to EN 14080:2013 (CEN 14080 2013) are used. The CLT specifications have bending strength $\mathrm{f}_{\mathrm{mk}}=24 \mathrm{MPa}$, and properties similar to $\mathrm{C} 24$ structural timber. The majority of the glulam is made out of untreated Norway spruce. Glulam that can be exposed to weathering is made of coppertreated lamellas from Nordic pine. Structural timber in the building modules and CLT is produced from Norway spruce.

The steel plates in the connections have steel grade S355 and are hot dip galvanized. The steel dowels are of type
A4-80 (acid-proof stainless grade). The use of galvanized steel ensures that rust water will not discolour the timber during the assembly. The stainless dowels are smooth and strong, and easy to install.

\subsection{Loading}

The Eurocode set of standards (CEN 1990 2002, CEN 1991 2002) with national annexes for Norway were used to determine the design loads. The wind loading turned out to be the dominating load in the design combinations. The calculated maximum wind speed became $\mathrm{V}=44.8 \mathrm{~m} / \mathrm{s}$ (CEN 1991-1-4 2002), giving corresponding wind pressure of $\mathrm{q}=1.26 \mathrm{kN} / \mathrm{m}^{2}$. The wind load was applied as a transient static load on all four sides of the building. In addition, wind load in the diagonal direction $\left(45^{\circ}, 135^{\circ}\right.$ etc. $)$ was checked. Wind tunnel tests were not found to be necessary due to the regular geometry of the construction. The U-shaped plan might lead to some local wind effects on the façade, but has probably minimal influence on the wind loading of the global structure.

Bergen lies in one of Norway's earthquake zones, but the ground acceleration is small compared to many other countries: $\mathrm{a}_{\mathrm{g} 40 \mathrm{~Hz}}=0.9 \mathrm{~m} / \mathrm{s}^{2}$ and design acceleration $\mathrm{a}=0.7 \mathrm{~m} / \mathrm{s}^{2}$. According to Norwegian regulations, earthquake loads are not necessary to incorporate in the design when wind prevails, which is the case here. It was therefore not necessary to design the building for seismic loads.

Self-weight is set to $4.5 \mathrm{kN} / \mathrm{m}^{3}$ for glulam and CLT and $25 \mathrm{kN} / \mathrm{m}^{3}$ for the concrete decks. The following live loads were applied:

$$
\begin{aligned}
& \text { Apartments: } 2.0 \mathrm{kN} / \mathrm{m}^{2} \\
& \text { Common areas: } 3.0 \mathrm{kN} / \mathrm{m}^{2} \text { corridors, stairs } \\
& \text { Balconies: } 4.0 \mathrm{kN} / \mathrm{m}^{2} \\
& \text { Gym: } 5.0 \mathrm{kN} / \mathrm{m}^{2}
\end{aligned}
$$

\subsection{Structural fire design}

The fire strategy report for this building states that the main load bearing system must resist $90 \mathrm{~min}$ of fire without collapse. This also applies to the prefabricated modules. Secondary load bearing systems, such as corridors and balconies, must resist $60 \mathrm{~min}$ of fire exposure. A collection of different fire protection measures are incorporated and among those are; fire stops on the facades for every second storey utilizing the horizontal glulam beams in the external trusses, fire painting with fire resistant lacquer type Teknosafe 2407 and Teknosafe 2467 of the wood in escape routes to avoid combustible surfaces, sprinkling for early suppression of fires, and elevated pressure in escape stair shafts for safe evacuation. 
The structural fire design is performed according to Eurocode 5 (CEN 1995-1-2 2004, CEN 1995 2004). The so-called reduced cross-section method has been applied, which determines the effective residual cross-section after charring (CEN 1995-1-2 2 2004). A notional charring rate of $0.7 \mathrm{~mm} / \mathrm{min}$ leads to a charring depth of $63 \mathrm{~mm}$ after $90 \mathrm{~min}$. Consequently, in the connection design all steel dowel ends have a minimum distance of $65 \mathrm{~mm}$ from any exterior glulam surface normal grain. It is hence not likely that the dowels will contribute to increased heat flux towards the steel plates. Furthermore, the steel plates are placed at a minimum distance of $108 \mathrm{~mm}$ from the outer surface, see Fig. 6. Although one must add $7 \mathrm{~mm}$ to get the effective residual cross-section, the part of the cross-section where the connections are located will probably remain nearly fully effective after $90 \mathrm{~min}$ of fire. It should be noted that there is a lack of timber design guidelines for fire requirements exceeding $60 \mathrm{~min}$ in the current European codes (CEN 1995-1-2 2004). It was found based on the use of similar design methods as presented in SP (2010), that in general for the considered building, fire scenarios are not governing design cases. However, some structural members have got increased cross-sectional size due to the fire evaluation. Furthermore, all gaps between connected timber members as well as the slots for steel plates are protected with intumescent fire seals.

\section{Assembly}

The assembly of "Treet" is mostly about installation of prefabricated elements on site. Optimizing the logistics and installation procedures are important to get a smooth building process. The manufacturer of the modules, Kodumaja together with the glulam producer Moelven Limtre use a tower crane as well as a climbing scaffolding system during the building erection. Temporary roofs are used to protect apartments, joints and timber from moisture during the building process.

A step-by-step model ensures that the building can be built according to the plans. Figure 7 shows the first steps in the building process, which is the foundation and the parking garage built in concrete. Next step is the stacking of 4 levels of pre-fabricated housing modules. The glulam frames are prefabricated in as large parts as possible, limited by transportation. The glulam frames are lifted in place in-between the modules and interconnected by dowels and the preinstalled slotted-in steel plates in step 3, Fig. 8.

Step 4 consists of the lifting and installation of the modules into the strengthened storey on level 5 , followed by step 6; the finalization of a concrete deck on top of level

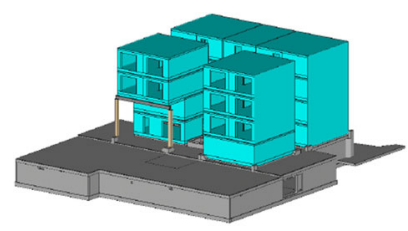

Fig. 7 Step 1 and 2

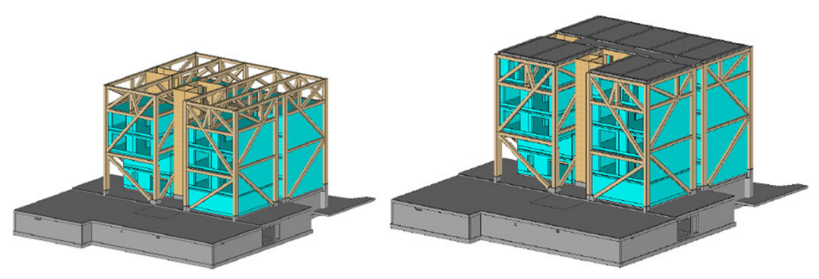

Fig. 8 Step 3, 4 and 5

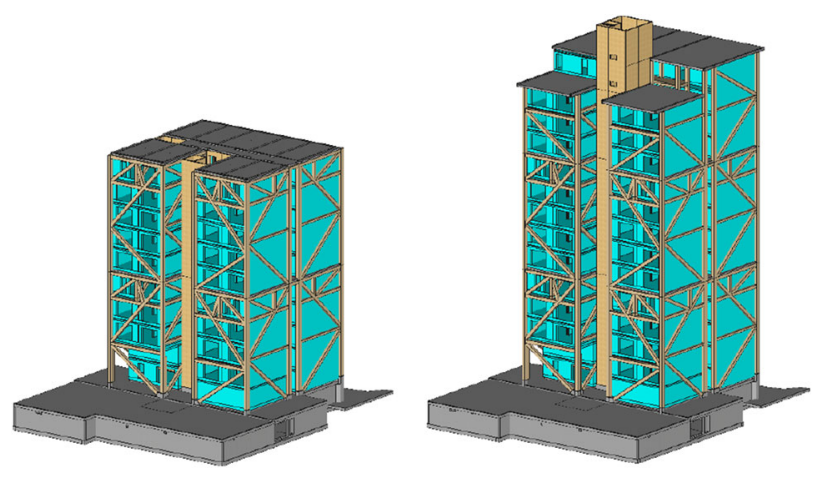

Fig. 9 Step 6 and 7, similar to step 2-5

5. This is the foundation for a new 4 level stack of modules, and the assembly process of step $2-5$ is repeated using level 5 as the foundation, and the result of this step 6 is depicted in Fig. 9. The concrete slab on top of the strengthened level 10 is used as the foundation for additional 4 levels of stacked modules. In step 8, the external weather skin of the building is attached to the glulam frames, and the building is finalized in step 9, which also involves glazing of balconies etc., see Fig. 10.

\section{Glulam load carrying frame}

This section deals with some of the design considerations and discussions which took place before the final design was worked out. It should be noted that these studies were performed on preliminary structural models different to the chosen final design. However, the basic ideas and structural concepts have not changed during the process; it has merely been an optimization process. 


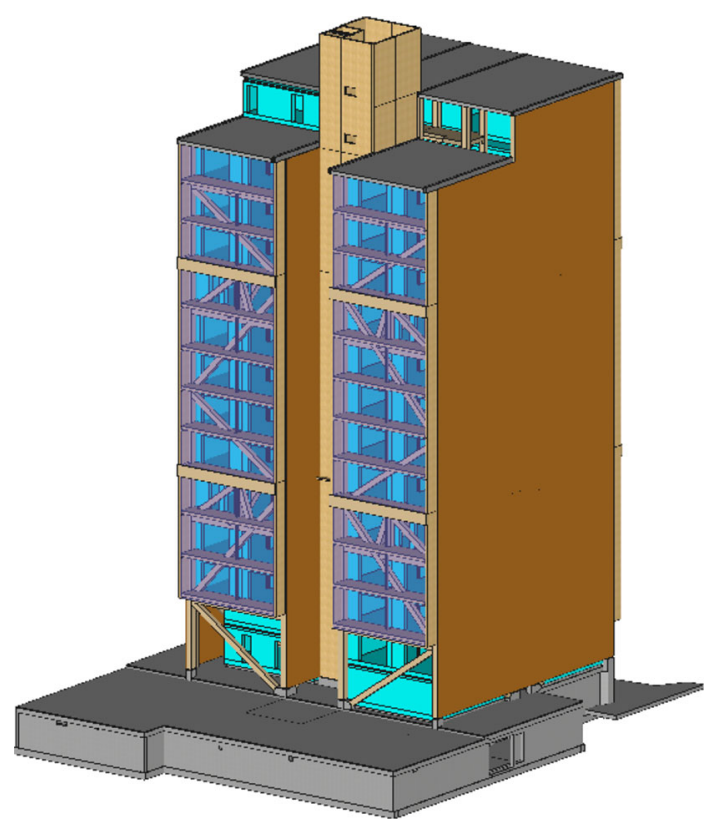

Fig. 10 Step 8 Cladding of gable walls, Step 9 Glazing

\subsection{Tall timber buildings built with glulam trusses}

"Treet" is a relatively high building with low structural weight and the building system has resemblance to similar buildings made by use of steel frames. A comparison to steel buildings is quite relevant since the ratio between Young's modulus and density is about 27 and 30 for steel and timber, respectively. Furthermore, the strength to density ratios are close to 0.045 and 0.070 , for steel and timber respectively. Although the material strength to density ratio is more than $50 \%$ higher for timber than for steel, the choice of cross-sections and connections may bring the ratio between the structural strength and mass quite close to that of steel. Consequently, for a glulam truss wooden building, the stiffness and mass will probably not be very different from a similar steel building.

A rule of thumb for steel buildings is that the lowest fundamental frequency can be estimated by $46 / H$, where $H$ is the height of the building in meter (CEN 1991-1-4 2002). As the height above the parking garage for "Treet" is about $45 \mathrm{~m}$, it is expected that the fundamental frequency is slightly above $1 \mathrm{~Hz}$. Tall buildings having their fundamental frequency around $1 \mathrm{~Hz}$ are not in the most powerful part of the wind spectra, but still a significant exposure to wind loading might occur and serviceability aspects become important.

The fundamental frequencies and corresponding vibrational modes of a building are dependent on the stiffness and masses as well as on how mass and stiffness are distributed. Little experience exists on serviceability aspects of tall timber buildings. However, large glulam trusses have been used in numerous modern timber bridges and the experience with their structural properties has been good.

The glulam members are interconnected by use of several slotted-in steel plates and numerous dowels, see the drawing in Fig. 5. Not all aspects of the behaviour of large dowel joints are well documented. Most investigations have dealt with the strength properties, and recent work on this topic can be found in for example, Sjödin et al. (2006, 2008). For use in timber bridges cyclic loading investigations for determination of fatigue properties have been performed (Malo et al. 2006), and design rules on cyclic loading are given in CEN 1995-2 (2004). However, for serviceability assessment also the stiffness properties are required.

\subsection{Stiffness of dowel connection with slotted-in steel plates}

In Eurocode 5 (CEN 1995 2004) simple design guidelines for evaluation of the stiffness of connections are given. The stiffness modulus $K_{s e r}$ is dependent on the connection type, the mean density of the timber $\rho_{\text {mean }}$, and the diameter $d$ in $\mathrm{mm}$. For a dowel fastener connecting steel and timber the stiffness modulus $K_{s e r}$ is given per dowel and shear plane by

$K_{\text {ser }}=2 \rho_{\text {mean }}^{1.5} \frac{d}{23}$

The Eurocode 5 (CEN 1995 2004) guidelines imply that the stiffness is proportional with the number of dowels and shear planes. However, it has been reported from experiments that the stiffness is not proportional to the number of dowels; it appears to be less (Siem 2014).

Figure 11 shows axial load vs. deformation relationships for two tests of glulam specimen with a dowel joint in each end (Malo 1999). Note that only one (the weakest) of the two connections in each specimen was completely driven into failure (end A or end B). The two slotted-in steel plates have a thickness of $8 \mathrm{~mm}$ and the diameter of the 12 dowels is $12 \mathrm{~mm}$, and hence these connections resemble the connection design of "Treet". From the tests results shown in Fig. 11, no initial slip without significant force was observed, but as the stiffness increases in the initial phase of the response curve, an initial effect is clearly present. The set-up of the test does not cause this as the displacement here is the relative displacement of the slotted-in steel plates relative to the surrounding wooden layer. Plausible causes can be nonlinear contact stiffness between the wood- and steel surfaces, unequal embedment stiffness distribution along the dowels and/or possible elastic bending of dowels. In general, initial slips in connections are caused by drilling inaccuracy, misalignments and possible damage to the wood surface during installation. 

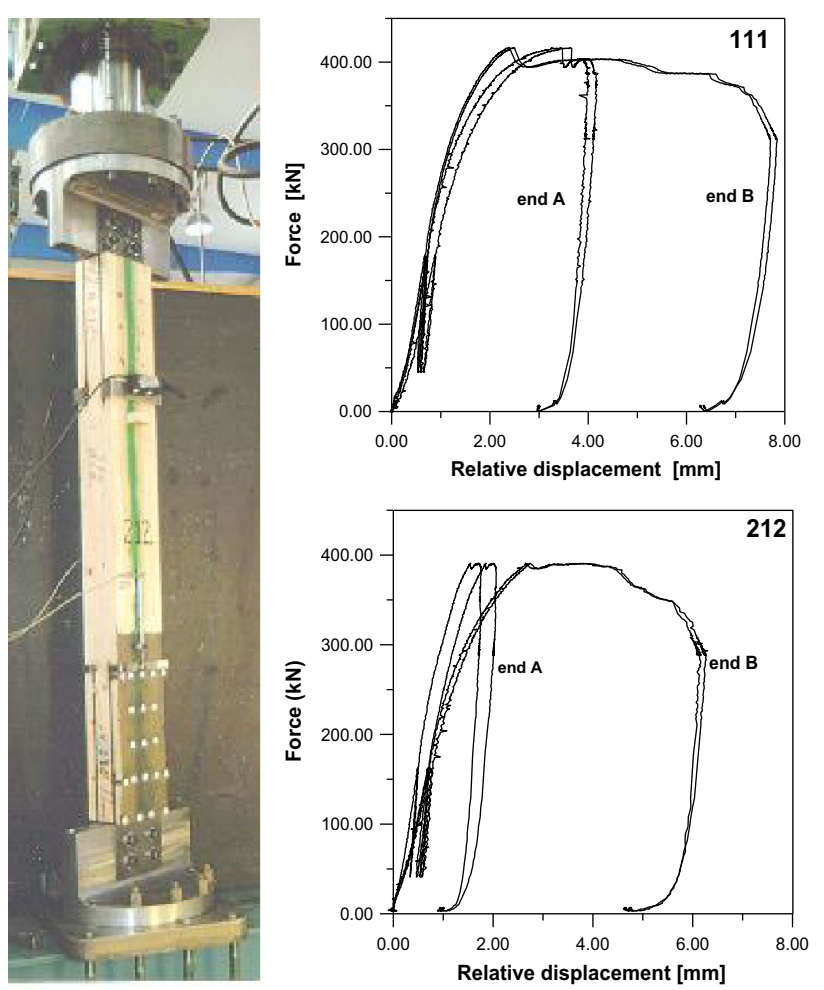

The stiffness of the tested connections compared to the stiffness of the glulam member with the same length as the connection; $k_{\text {rel }}=K l_{\text {connection }} / A E$, varied in this case in the range $0.35\left(K=K_{\text {sec }}\right)$ to $1.0\left(K=K_{c y c}\right)$, depending on how the stiffness is defined.

\subsection{Sensitivity to stiffness of connections in the glulam frame}

To evaluate how different parameters influence the global dynamic response, a parametric study has been performed (Utne 2012). In this study, the structural system was modelled in Abaqus numerical FEM code (Simulia 2012).

There will be very few connections in the vertical columns of the glulam frames and the effect of this is believed to be negligible. It is more likely that the flexibility of the joints connecting beams and diagonals to the columns in the external truss may influence the horizontal deformation of the structure, and also change the dynamic performance. Several approaches to model the connections were done to investigate how the axial and rotational stiffness change the performance of the model.

Initially, the load-carrying glulam frame was modelled with all nodes tied, i.e. all members in a joint were forced to have the same rotations. Next, all nodes were allowed to have separate rotations, i.e. the nodes were modelled as hinges. Insignificant differences in deflections and natural frequencies were obtained from the two extreme cases with respect to rotational stiffness of the joints. From this it was concluded that the structural response is very close to a pinned truss-work, and there is no need for evaluation of the rotational rigidity of the connections as long as the structural design does not introduce large eccentricities at the joints. The load carrying glulam frame may be well represented both with pinned or tied joints in the structural model.

The axial stiffness of the joints will have larger impact on the overall structural response since the glulam frame behaviour is close to a truss-work. The complete model of the case "Treet" was very complex with more than 200 joints, and to modify all the connections is therefore a cumbersome process. During the initial modelling process the numerical model was equipped with separate elements and material types at all locations close to joints. The length of these special elements was typically equal to the height of the physical structural members (400-500 mm). For example, a diagonal element connected to two joints had a special element and material type at both ends of the structural member. In this way the model was parameterized and various effects could be studied by a simple change of these special elements or the associated material type behaviour.

The effect of the axial stiffness of connections was studied by reducing cross-sectional area of the special end 
elements. Since the axial stiffness is linear with the crosssectional area, the ratio between the reduced sectional area to the original member area is directly comparable to $k_{r e l}$, i.e.; $k_{\text {rel }}=A_{\text {red }} / A_{\text {member }}$.

To evaluate the sensitivity of the model regarding stiffness of the connections, member segments with reduced area in the range of $10-40 \%$ of the original member cross-sectional area was investigated. This gives a reasonable interval around a possible reduced stiffness of the connection.

The effect of reduced stiffness in the connection on the natural frequencies for the three lowermost frequencies is shown in Fig. 12. The reduction of the stiffness in the beam segments has only significance on the fundamental frequencies when the stiffness of the connections is smaller than about $25 \%$ of the member stiffness, i.e. $k_{r e l}<0.25$, cf. Fig. 12. This is partially explained by the short length of the segments compared to the beams. With lengths of 8-12 $\mathrm{m}$ for the beams and diagonals, a $400 \mathrm{~mm}$ segment at each end is equivalent to less than $10 \%$ of the total length. Thus reducing the stiffness in the segments has small effect on the global stiffness. Furthermore, no changes in the mode shapes were obtained.

Reduced stiffness at the connections may also give an increase of the acceleration at the top of the structure. In this case it was found that a reduced stiffness $k_{r e l}=0.2$ gave about $10-15 \%$ increase of the maximum accelerations. Nevertheless, it must be emphasized that the stiffness of the connections study was performed assuming that all connections were similar.

\subsection{Damping properties of glulam members}

Buildings subjected to fluctuating wind might very well start to vibrate and lead to discomfort of the occupants. For a given building design, the accelerations will depend on the frequency and the vibrating mass, and to a large extent

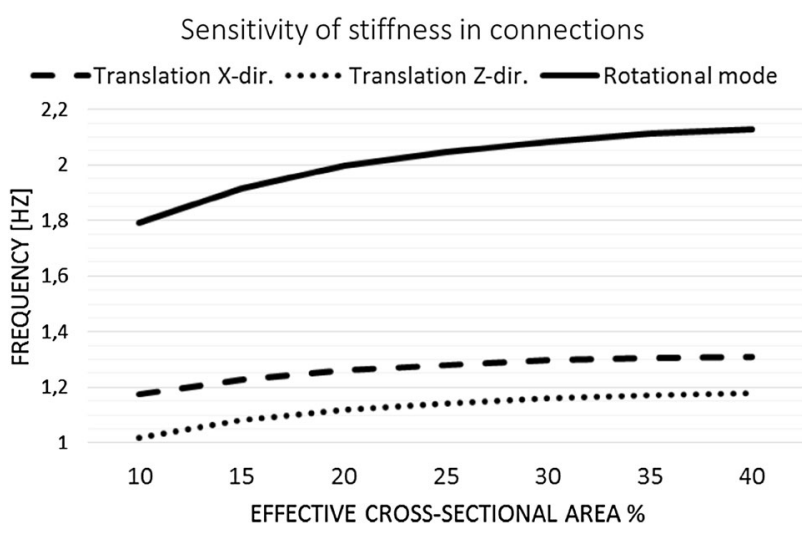

Fig. 12 Effect of reduced stiffness in beam segments on frequency also on the energy dissipation within the building since this is the way a building can limit the energy put into and stored in the building due to dynamic loading. For lightly damped buildings, which in fact represent the usual case for buildings, a small change of the damping properties might give a large influence on the accelerations of the building. Today, it is realized that the knowledge of damping properties of large timber buildings are insufficient, a fact that has been recognized by several authors (e.g. Chapman et al. 2012).

Several measures of damping occur in the literature and for lightly damped linear systems the most used terms are related in the following way;

$\xi=\delta / 2 \pi=\eta / 2$

here $\xi$ is equivalent viscous damping, $\delta$ is the logarithmic decrement and $\eta$ is the so-called loss coefficient. Since equivalent viscous damping models are easily applicable to numerical analyses of structures by the FEM numerical codes, this is the preferred choice herein.

It should be noted that the numbers discussed for damping herein, are solely estimations and only in situ measurements can reveal the real numbers for a structure under considerations.

The total equivalent viscous damping may be approximated by

$\xi=\xi_{\text {struct }}+\xi_{\text {mat }}$

The material damping in wooden members $\xi_{m a t}$ is believed to be due to internal friction in the materials, while $\xi_{\text {struct }}$ is caused by friction between members and other parts as well as friction and energy dissipation in connections, for example between dowels and wooden material.

For glulam made of Norway spruce, a recent investigation has been carried out to quantify the material damping and the major findings were that for members and deformation modes without significant shear stresses the material damping is of the order of $\xi_{\text {mat }}=0.005$.

For High beams and short spans, i.e. in cases where shear deformation contributes significantly to the total deformation, the material damping increases to about $\xi_{\text {mat }}=0.011$. More on these experiments can be found in Labonnote et al. (2013b) and the evaluations are given in Labonnote et al. (2013a). These numbers correspond well to similar investigations on Norway spruce beams, see for example Spycher et al. (2008), where $\xi_{\text {mat }}=0.0051$ was found for flexural vibration, i.e. where axial strain was the cause of deformation.

The glulam structure is designed to work as a truss. The connections are without eccentricities, and hence the glulam members will mainly be subjected to axial straining. It 
is therefore likely that the material damping in the glulam members will be about $\xi_{\text {mat }}=0.005$.

\subsection{Damping properties of dowel connections}

This type of damping is usually due to friction between mating surfaces of the dowels and the surrounding wooden material, and in some cases crushing, cracking or compression of the wood due to high concentration of stresses around the dowels. It is natural to classify this type of damping as structural damping since it originates from interaction of different materials and are dependent on the structural lay-out of the connections.

Figure 11 shows load-deformation relationships for two tests of a glulam specimen with a dowel joint in each end. The load level in a serviceability state will be in the range $20-40 \%$ of the ultimate load and it may be observed from the response plots in Fig. 11 that the response is fairly linear in the range from 50 to $200 \mathrm{kN}$.

An unloading-reloading cycle has been performed in the range $10-40 \%$ of the ultimate load and the response was nearly linear with very small amount of dissipated energy enclosed by the hysteretic loops. Consequently only small amount of energy dissipation is expected for load cycles in the serviceability domain for a connection with slotted-in steel-plates and dowels.

For a single dowel embedded in wood some evaluations have been performed and reported (see Reynolds et al. 2012). Although not directly comparable to connections with slotted-in steel-plates and dowels, it may serve as an indication of the level of damping. The obtained logarithmic decrement of damping for non-reversed loading is about $\delta=0.12$ or by use of Eq. (2); an equivalent viscous damping ratio will be about $\xi_{\text {struct }}=0.019$.

\subsection{Damping properties of external walls}

In between the glulam frames in the external walls there are secondary structural systems transferring the wind loading to the main load carrying system. It consists of horizontal beams and vertical columns forming a rectangular pattern. The vertical members span typically over two levels, but are interrupted by the diagonal main glulam members, cf. Fig. 3 . On the secondary structural systems, which are also made of glulam, horizontal Z-profiles of steel are attached, which is used to fasten the exterior metal sheet cladding. Due to the large thickness of the external walls, the windows are equipped with steel cassettes which form niches around the windows. These are attached partly to the main load carrying system, or the secondary system. The south façade has glazing structures attached to the external surfaces. In this way the main load carrying structure has a lot more interconnections than solely at the structural joints.
An investigation of the cause of damping in timber floors consisting of joists and sheet materials (plates), reveals that roughly half of the energy dissipation is due to material damping and the other half is caused by structural damping, i.e. caused mainly by energy dissipation in connections and interaction between mating surfaces (Labonnote et al. 2015). The results also showed that the total equivalent viscous damping ratio was in the range between 2 and $3 \%$. It was pointed out that the amounts of especial structural damping increases with higher vibrational modes, i.e. with increasing shear deformation in the vibrational modes (Labonnote et al. 2015). For comparison, Eurocode 5 (CEN 1995 2004) recommends $\xi=0.01$ for timber floors if no other value is known.

A floor structure is mainly subjected to bending deformation, while the governing deformational mode for the main glulam frames will be closer to shear panel deformation, see the plots of the lower transversal fundamental modes in Figs. 19 and 20, mode one and two respectively. The third mode is a torsional mode. For timber bridges with mechanical joints, Eurocode 5 part 2 (CEN 1995-2 2004) recommends the use of $\xi=0.015$, while Eurocode 1 (CEN 1991-1-4 2002) proposes values up to $1.9 \%$ for timber bridges. Usually the timber bridges have no sheeting or other structural elements, which dissipate energy due to shear deformation between components.

On this background the following estimations have been done:

- The material damping in the glulam members is probably in the range $\xi_{\text {mat }}=0.005-0.010$.

- The structural damping in dowelled connections is probably in the range $\xi_{\text {struct }}=0.010-0.020$.

- The total equivalent viscous damping ratio for the glulam structural frames will probably be in the range $\xi=0.015-0.025$.

It is to be noted that these damping ratios are solely estimations, or best engineering judgement for the time being. Only full scale measurements will reveal the real damping ratios. For the final design a total equivalent damping ratio $\xi=0.019$ has been used.

\section{Dynamic properties of prefabricated residential modules}

To the knowledge of the authors, the idea of repeated stacks of residential wood-based modules in vertical direction mounted on floors lying in between has not been used before. Due to the lack of necessary information on dynamic behaviour of residential building modules, the responsible engineering consultant Sweco Norway AS contacted Norwegian University of Science and 
Technology, NTNU, to discuss the challenges regarding the dynamical properties.

The modules would be produced and delivered by the Estonian company Kodumaja. After an initial evaluation it was decided to perform full-scale non-destructive dynamic testing of modules in cooperation with the producer. At this stage the modules were not produced, so the tests had to be performed on modules very similar to the modules that were planned to be used in "Treet". The testing of the modules was performed by NTNU in September 2012 at the factory of Kodumaja in Tartu, Estonia.

\subsection{Test setup, methods and instrumentation}

Figure 13 shows the two by two stack with four (in total) prefabricated residential modules which were subjected to non-destructive testing. The tests were performed at the module factory location (Jørstad and Malo 2012). It should be noted that the noise to signal ratio was too high to give reliable measurements during the working hours of the factory, consequently all measurements had to be performed within a very short time window.

Two different test protocols were used; an experimental modal analysis (MA) protocol, and a system identification (SID) protocol. The protocols require slightly different equipment and setups. However, the practical difference in carrying out MA and SID tests are small. An instrumented impact hammer was used for both protocols to excite the structure. The dynamic response was measured by use of accelerometers. The main difference between the protocols is related to the data processing after the time series has been recorded, as well as the number and locations of impacts and accelerometers.

For the MA test, the impacts of the hammer were measured by the built in load cell and the accelerations measured by one single piezoelectric accelerometer,

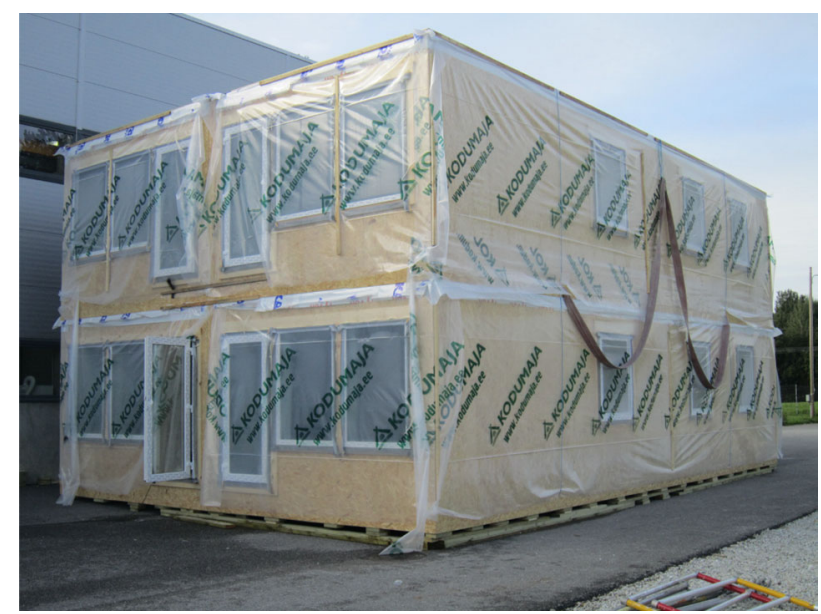

Fig. $132 \times 2$ modules test setup located at point "P" as shown in Fig. 14 for the short front side, and in Fig. 15 for the long side of the modules.

The structures were excited according to a pre-programmed grid in the MA software (roving hammer method). The grid was quite similar to the grid of straingauge accelerometers also shown by the added numbers for the short and long sides shown in Figs. 14 and 15, respectively. The impacts on the modules were performed on one side at a time, and the measured response from the accelerometers was always measured on the rear side relatively to the impacted side of the modules.

For the SID test, the excitations were also imposed by the hammer, but the impact force was not recorded, nor was it required for the analysis. The grid of six tactically located accelerometers measured the accelerations and a computer recorded the acceleration time histories.

To get useful measurements, it is important that the impacts hit the structural framing, and that the accelerometers are attached firmly to the structural framing and not on local elements. Note that the location of the accelerometers used for MA and SID protocols do not coincide.

\subsection{Processing of experimental data}

The modal parameters for all modes within the frequency range of interest constitute a complete dynamic description of the structure. Any free or forced dynamic response of a structure may be reduced to a discrete set of modes. The

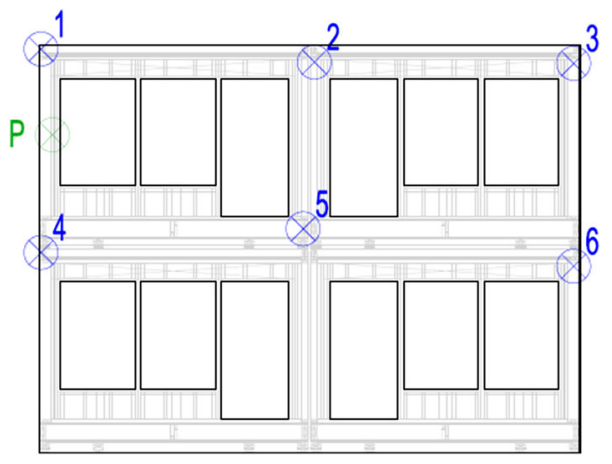

Fig. 14 Location of accelerometers on short front side

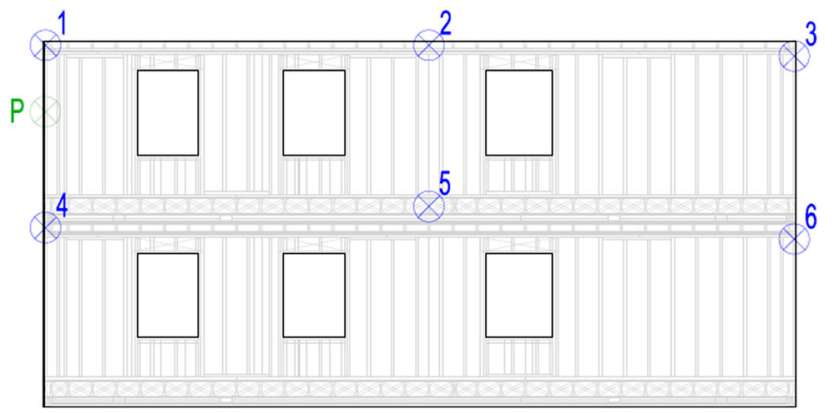

Fig. 15 Location of accelerometers on long side 
modal parameters are modal frequency $\omega_{r}$, modal damping $\xi_{r}$ and the mode shape vector $\boldsymbol{\Psi}_{r}$, for mode number $r$.

The full frequency response relationships may be expressed by matrix $\mathbf{H}$, and consequently;

$$
\left\{\begin{array}{c}
X_{1} \\
X_{2} \\
\vdots \\
X_{n}
\end{array}\right\}=\left[\begin{array}{cccc}
H_{11} & H_{12} & \ldots & H_{1 n} \\
H_{21} & H_{22} & \ldots & H_{2 n} \\
\vdots & \vdots & \vdots & \vdots \\
H_{n 1} & H_{n 2} & \ldots & H_{n n}
\end{array}\right]\left\{\begin{array}{c}
F_{1} \\
F_{2} \\
\vdots \\
F_{n}
\end{array}\right\}
$$

$H_{i j}$ terms may be defined as:

$H_{i j}(\omega)=\frac{X_{i}(\omega)}{F_{j}(\omega)}=\frac{\text { Response “ }{ }^{\prime \prime}}{\text { Excitation “ ‘j” }}$

where $X_{i}(\omega)=$ Fourier transform of the response $x_{i}(t)$, and $F_{j}(\omega)=$ Fourier transform of the excitation $f_{j}(t)$.

The knowledge of a unique row (roving hammer method) is usually enough to characterize all the vibrational modes of a structural system. However, measurements of a row or column of the frequency response matrix is not sufficient for determination of all the vibrational modes of a system when there are several modes for the same frequency, e.g. for symmetrical structures.

\subsubsection{Modal parameter identification}

Experimental modal analysis (MA) (Ewins 2000) is used for determining the fundamental frequencies, the damping ratios and the mode shapes, assuming small total damping values. The frequency response function $H$ relates the input signal spectrum $F$ from the hammer's load cell and the output signal spectrum $X$ from the accelerometer.

The parameter identification method is based on the Frequency-Domain Direct Parameter Identification fitting method, which is a frequency domain multiple degree-offreedom modal analysis method suitable for narrow frequency band and well separated modes.

A linear average of the frequency response function over several impacts is performed. Identification of transfer function models is performed by curve fitting the averaged frequency response function with suitable analytical expressions, given by:

$$
\begin{array}{r}
\text { with }\left\{\begin{array}{l}
\left(\psi_{i k} \psi_{k}\right)_{r}=\sum_{r=1}^{n} \frac{\left(\psi_{i} \psi_{k}\right)_{r}}{\left[\omega_{r}^{2}-\omega^{2}+2 j \xi_{r} \omega_{r} \omega\right]} \\
\omega_{r}=\text { undamped natural frequency } \\
\xi_{r}=\text { viscous modal damping ratio }
\end{array}\right.
\end{array}
$$

where $r$ is the mode number, $n$ is the total number of modes, and $j=\sqrt{-1}$. The natural frequency and the modal viscous damping ratio are directly extracted from Eq. (6). The mode shape vectors $\boldsymbol{\Psi}_{r}$ are extracted as:
$\Psi_{r}=\left[\begin{array}{llll}\left(\Psi_{1}^{2}\right)_{r} & \left(\Psi_{1} \Psi_{2}\right)_{r} & \cdots & \left(\Psi_{1} \Psi_{n}\right)_{r}\end{array}\right]$

The estimation of the modal parameters from the frequency response function is done by minimizing the squared difference between the assumed analytical function and the measured frequency response function.

\subsubsection{System identification}

System identification (SID) in structural engineering is an advanced form of a curve fitting method for estimating dynamic properties of structures (Van Overschee and De More 1996). Besides experimental evaluations of dynamic properties of structures, SID is also used to monitor ready built structures in order to get more information about their dynamic properties. The information gained from such monitoring can be used to improve numerical models for similar structures in the future.

There are several available algorithms for system identifications. Some are based on the least square method, the extended Kalman filter or the maximum likelihood method. The method used here is called the Numerical Subspace State Space System Identification method (N4SID). This is a least square method, which is part of the System Identification Toolbox in MATLAB (The MathWorks, Inc.). It is easy to use and it is considered to be robust due to algorithms based on standard numerical linear algebra. The method can handle both input-output measurements and output-only measurements.

\subsection{Test results}

The three measured mode shapes corresponding to the three lowest fundamental frequencies are visualized in Fig. 16.

The mode shapes are created from the measurements obtained from the MA protocol. Experimental results from both test protocols are given in Table 1.

There are differences in the results between the two protocols; the fundamental frequencies are about $0.5 \mathrm{~Hz}$ lower in SID protocol than in the MA protocol. Furthermore, the measured modal damping ratio with the SID protocol appears to be about $0.5 \%$ higher than that obtained from the MA protocol. However, both methods seem to be consistent with themselves as they deliver

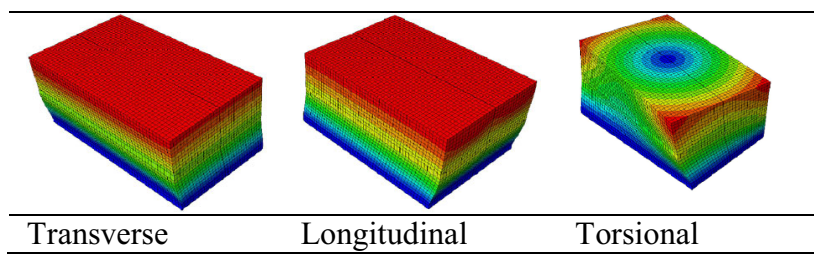

Fig. 16 Measured mode shapes 
Table 1 Measured results from two different protocols

\begin{tabular}{lllcc}
\hline Impact side & Mode & Protocol & Frequency $(\mathrm{Hz})$ & Damping $(\%)$ \\
\hline Long & Transverse & MA & 5.5 & 3.2 \\
& & SID & 4.9 & 3.9 \\
& Deviation & & 0.6 & -0.70 \\
& Torsional & MA & 10.7 & 3.1 \\
& & SID & 10.2 & 3.2 \\
& & & 0.5 & -0.1 \\
Short & Meviation & MA & 9.0 & 6.0 \\
& Longitudinal & SID & 8.5 & 6.7 \\
& & & 0.5 & -0.7 \\
& Deviation & MA & 10.7 & 2.8 \\
& Torsional & SID & 10.2 & 3.4 \\
& & & 0.5 & -0.6 \\
\hline
\end{tabular}

identical results for the torsional mode regardless of which side they were impacted and measured. Due to limited time at the test side this could not be further explored during the testing period, and no explanation is given. It might be due to the fact that quite different equipment was used for the two protocols, the locations for the accelerometers were not coinciding, and the noise-to signal ratio was not fully satisfactory. However, the standard deviations of the measurements did not indicate non-valid measurements.

\section{Stacks of prefabricated modules}

Although the dynamic properties of a stack of $2 \times 2$ residential modules were determined, the properties of the modules planned for "Treet" had to be estimated too. Two major issues were pointed out:

1. What are the dynamic properties of the stacks of residential wooden modules to be used in "Treet"?

2. How to incorporate the effects of the modules in the global structural analysis?

Very detailed FEM models of the tested modules were worked out (Jørstad 2013). The models included studs, beams, sheeting and any part with significance for the dynamic behaviour. These models were calibrated to have the same dynamical properties as the tested modules. During this work it appeared that the dynamic properties were sensitive to the way the actual modules are assembled and it should be noted that the measured dynamical properties might be of little value for other types of modules using different assembly or parts. Same type of advanced FEM numerical models were also built for the modules to be used in "Treet", and in turn used to estimate the properties of the planned "Treet" modules.

The advanced Abaqus FEM models were far too detailed and complicated to be incorporated in the global analysis of the whole building, instead simplified models based either on shear frames or trussed frames were calibrated to have similar dynamical properties. In this calibration the two translational modes were given priority on the expense of the torsional mode.

The tested modules had a base of $4 \times 12.5 \mathrm{~m}^{2}$ and a weight in the range $91-95 \mathrm{kN}$ depending on whether it was a ground module or not. The modules that are to be used in "Treet" are $4 \times 8.7$ and $5.3 \times 8.7 \mathrm{~m}^{2}$, see Fig. 4 for a typical plan of the building. Module $\mathrm{A}$ and $\mathrm{B}$ are $4 \times 8.7 \mathrm{~m}^{2}$ and module $\mathrm{C}$ is $5.3 \times 8.7 \mathrm{~m}^{2}$. The difference in weight was taken into account and $50.5 \%$ of the mass was added to the ceiling of the model and $49.5 \%$ to the floor, based on the weight distribution of a module. The various variants of stacks are given together with the corresponding fundamental frequencies in Table 2.

It is quite clear that the dynamical properties of stacked modules are dependent on the number of stack modules in vertical direction, but not in the horizontal direction, with the exception of the torsional mode. Furthermore, the modules behave much softer in the transverse direction (of the modules) and therefore have lower fundamental frequency in that direction.

It should also be noted that the stacks of modules appear to have considerably higher fundamental frequencies than those of the overall glulam load-carrying frame, which are estimated to about $1 \mathrm{~Hz}$.

Table 2 Actual configuration of stacked modules

\begin{tabular}{llll}
\hline Configuration & \multicolumn{2}{l}{ Vibrational mode $(\mathrm{Hz})$} \\
\cline { 2 - 4 } Hor. $\times$ vert. & Transverse & Longitudinal & Torsional \\
\hline $2 \times 3$ stack & 3.5 & 4.8 & 6.3 \\
$2 \times 4$ stack & 2.6 & 3.6 & 4.7 \\
$5 \times 4$ stack & 2.6 & 3.6 & 3.9 \\
\hline
\end{tabular}




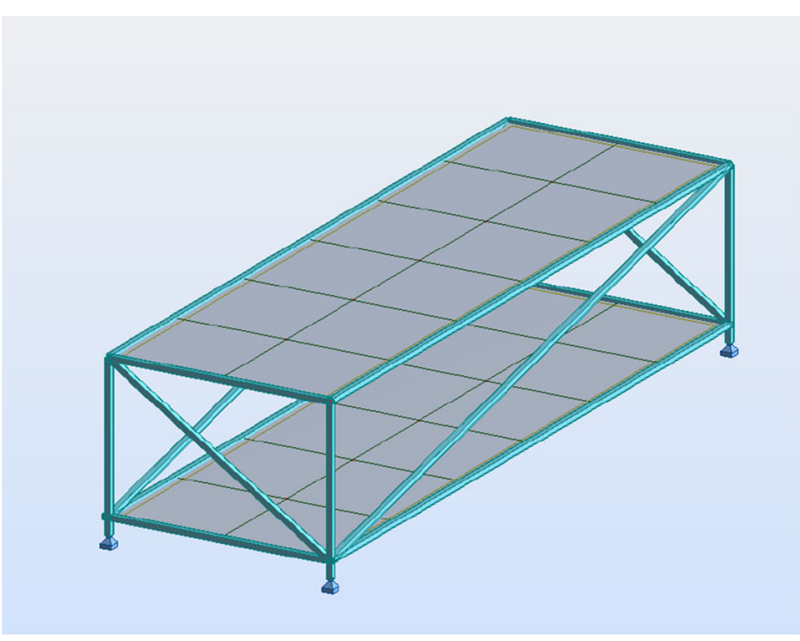

Fig. 17 Simplified FEM-model of a building module

In the final design verification it was decided to use the truss-frame variants of the simplified FEM-models. The walls in the modules were represented by vertical beamelements and braces. For the floors and ceilings stiffer shell-elements were used. The mass distribution of the modules were incorporated into the shell-elements, see Fig. 17 for visualization. All beams and braces were pinned at the joints. In this way horizontal stiffness was only modelled by the braces. The stiffness of the braces was tuned to harmonize with the test result.

\section{Structural modelling}

The computer software Robot Structural Analysis Professional 2013 was used for the global structural analyses of the building, and a visualization of the global structural model is presented in Fig. 18. Excel spreadsheets and hand calculations were used to perform the design code checks according to Eurocode 5 (CEN 1995 2004).

"Treet" consists of a vertical glulam truss work carrying two intermediate platforms, denoted "power storeys". A "power storey" consists of a horizontal glulam truss work carrying a concrete slab, see Fig. 2. The slab serves as foundation for additional four storeys of modules. A single storey of residential modules is also placed inside each of the "power storeys", cf. Fig. 18. Four additional storeys are placed directly on the slab above the basement. Apart from the "power storey", the modules are only connected to the load carrying structure at the base (the concrete slabs). A concrete slab was added to the top level of the building as well in order to interconnect the different truss works, and to add more weight to the structure. This gave the building higher modal masses and decreased the accelerations. The CLT-elements in the shafts are not included as structural elements in the design. They are only

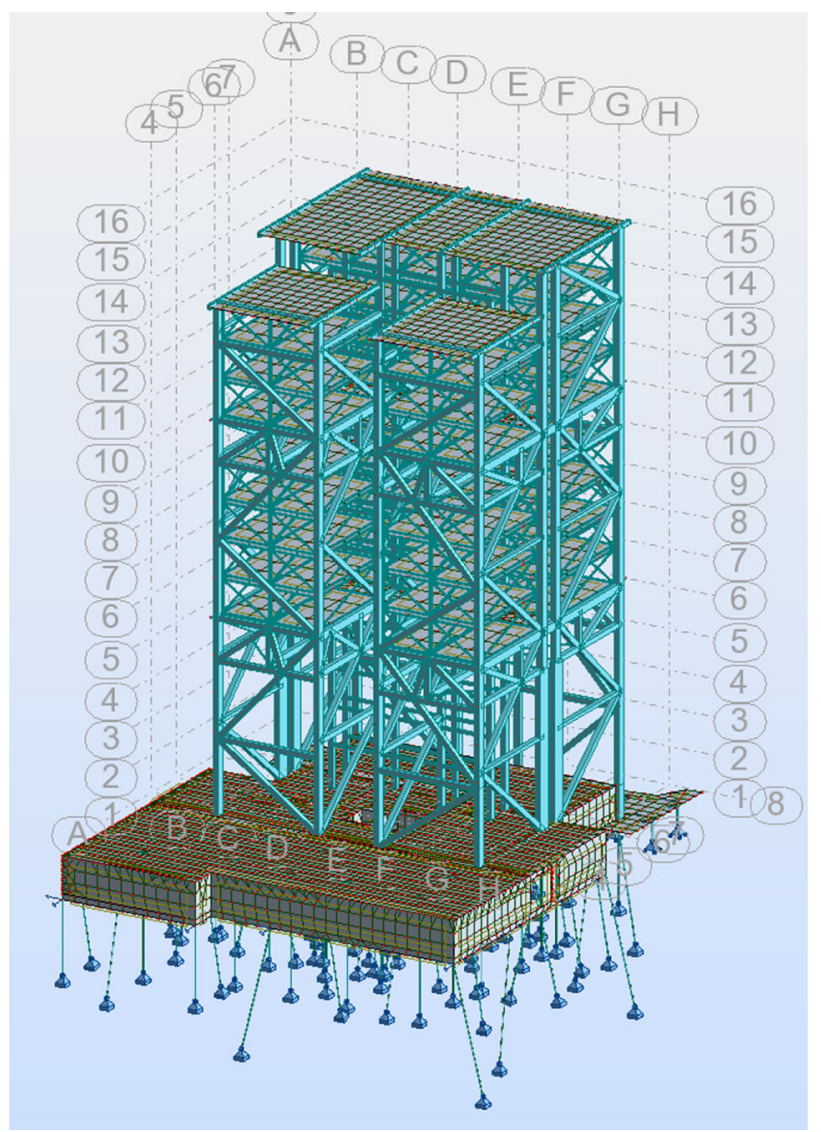

Fig. 18 Global FEM-model of "Treet"

included as vertical bearing for the stairs and elevators. The bottom levels of a "power storey" are interconnected using steel braces to avoid local deflections and vibrations.

The ULS check was decisive for most structural dimensions. A few elements are governed by fire design. Since the building is relatively light, much attention was put into the dynamic considerations.

The highest compression force in a column is computed to $4287 \mathrm{kN}$. The highest tensile force in a column became $296 \mathrm{kN}$. The highest tensile force in a diagonal was calculated to $930 \mathrm{kN}$.

The effect of possible slip at the joints is not included in the design, but the sensitivity to joint slips was investigated in the sensitivity study and it was concluded that in this case it will have minor impact on the force distribution as well as on the fundamental frequencies and level of displacements. Furthermore, a typical column of $45 \mathrm{~m}$ height is delivered in three pieces, while all diagonals will be produced in full length. Consequently, there will be few connections where slip can occur.

Further, the global analyses of the dynamic behaviour of the building were made using Robot Structural Analysis Professional 2013. The glulam trusses were modelled with their actual geometry and stiffness, the grade of the glulam 
is GL 30c according to EN 14080 (CEN 14080 2013). The trusses were modelled with pinned joints between all members.

The concrete slabs were modelled using shell elements with representative mass and stiffness properties. The foundation of the building is a concrete basement supported on steel core piles inserted into the underlying bedrock approximately $5 \mathrm{~m}$ below the basement. The steel core piles and basement were also modelled with their actual geometry and stiffness properties. In the dynamic analysis, the concrete weight of the basement was set to zero and the basement was fixed in the horizontal direction at the bottom level. The basement is stiff compared to the truss work. The dynamic analysis includes solely axial stiffness of the piles and vertical elements of the basement structure. This choice was made in order to avoid local effects from the basement structure leading to uncertainties in the interpretation of the vibrational properties.

Only the modules from the first "power storey" and above were included in the FEM-model. The first four levels of stacked modules from the basement will not affect the building response because they are not connected to the truss work. The modules in the "power storeys" were only modelled by added mass to the truss work.

The four levels of stacked modules at the concrete slabs were modelled as described previously. The modules were placed on a load-distributing beam on the concrete slab. This represented the bottom sill of the module. This was done in order to avoid local effects on the slab at the modules "feet". This is the only connection between the modules and the slabs and truss work structures.

The modules cannot move independently because they are connected to each other in all adjoining joints. This is modelled as short elements between the modules.

All modules should carry a live load of $2 \mathrm{kN} / \mathrm{m}^{2}$, and $30 \%$ of this load was added as additional mass in the modal analysis. The mass was applied to the floor of each module. Similarly, corridor elements, storage rooms etc. were modelled as added mass at their respective positions.

\section{Design verification for wind loading}

The following questions were of major concern;

1. Will the stacks of modules give positive or negative effects on the dynamical response to fluctuating wind loading on the building?

2. Should the modules be fastened to the main load carrying system at more locations than at the foundation plates?

\subsection{Dynamic effects of wind}

The wind loading part of Eurocode (CEN 1991-1-4 2002) gives guidelines on how to calculate the peak accelerations. ISO guidelines (ISO 10137 2007) give recommended design criteria for wind-induced vibrations to evaluate the serviceability of the building, while Boggs (1995) gives guidance for human response to vibrations.

The general calculation of the standard deviation of the wind-induced accelerations in the horizontal direction, $\sigma_{a x}$, is given in Annex C in CEN 1991-1-4 (2002), i.e.:

$$
\begin{array}{r}
\sigma_{a x}(Y, Z)= \\
c_{f} \cdot \rho \cdot I_{v}\left(Z_{s}\right) \cdot V_{m}^{2}\left(Z_{s}\right) \cdot R \cdot \frac{K_{y} K_{z} \Phi(Y, Z)}{\mu_{r e f} \Phi_{\max }}
\end{array}
$$

where $c_{f}=$ force factor, $\rho=$ air density, $I_{v}=$ turbulence intensity, $V_{m}=$ characteristic wind velocity on site, $R=$ resonance part of the response, $K_{y}, K_{z}=$ constants given in CEN 1991-1-4 (2002), $\Phi(y, z)=$ mode shape at a point $(y, z)$, $\mu_{\text {ref }}=$ equivalent mass per square meter and $\Phi_{\max }=\max$ amplitude of the mode shape. By multiplying $\sigma_{a x}$ with the peak factor $k_{p}$ the characteristic peak acceleration for a point $(\mathrm{y}, \mathrm{z})$ is obtained. Factor $k_{p}$ is given by CEN 1991-1-4 (2002):

$k_{p}=\sqrt{2 \ln (v \cdot T)}+\frac{0.6}{\sqrt{2 \ln (v \cdot T)}}$

where $v=$ frequency of the evaluated mode shape and $T=600 \mathrm{~s}$. The peak acceleration and the frequency can then be plotted into evaluation curves for wind-induced vibration given in ISO 10137 (2007), see Fig. 21.

The module testing showed that a stack of four modules has much higher natural frequencies than the global response of the building. Therefore it was decided to avoid other connections than between the modules and the slab foundation. Figure 19 shows the first vibrational mode of the building and Fig. 20 the second; with fundamental frequencies 0.75 and $0.89 \mathrm{~Hz}$, respectively. The modules follow the vibrations of the slabs mainly like rigid bodies.

Only the lowest transversal modes 1 and 2 were of interest with respect to wind-induced vibrations of the building and the further evaluations were based on these two modes. The external cladding and glazing of the building are attached to the truss frame. The wind load will hence not affect the modules directly. The equivalent mass per square meter, $\mu_{r e f}$, is needed to calculate the standard deviation, $\sigma_{a x}$, see Eq. (8). $\mu_{\text {ref }}$ can be calculated weighting the mass distribution with the mode shape $\Phi_{1}(y, z)$ by; (see Annex F in CEN 1991-1-4 2002):

$$
\mu_{\text {ref }}=\frac{\int_{0}^{h} \int_{0}^{b} \mu(y, z) \cdot \Phi_{1}^{2}(y, z) d y d z}{\int_{0}^{h} \int_{0}^{b} \Phi_{1}^{2}(y, z) d y d z}
$$




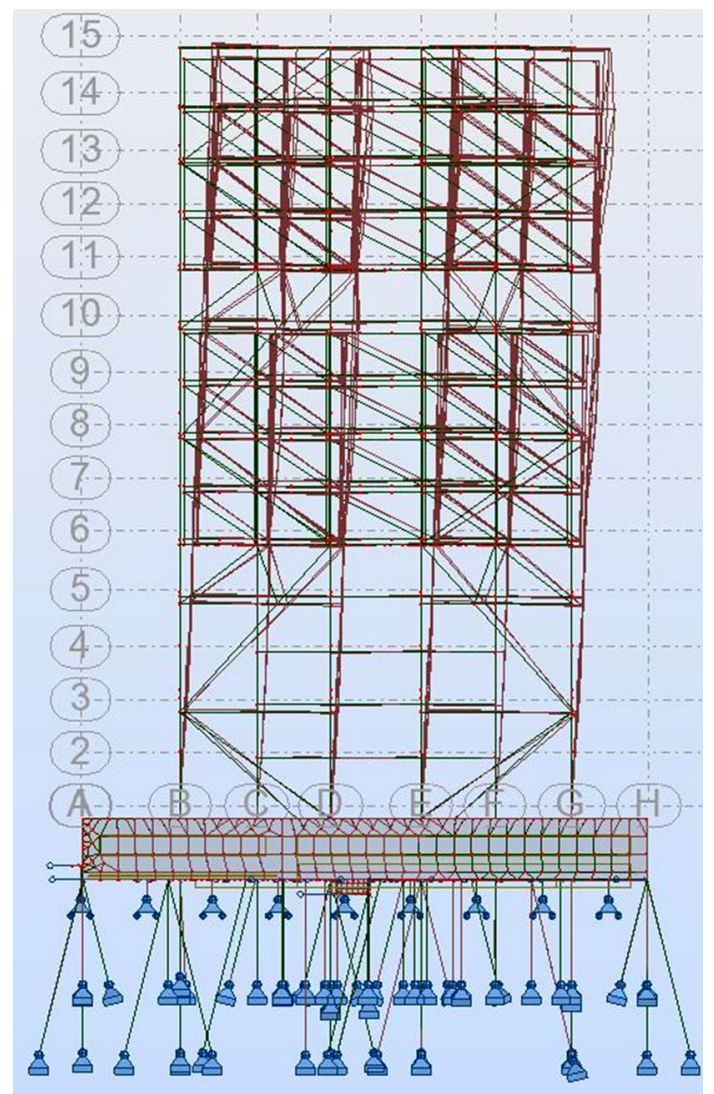

Fig. 19 Mode 1 East-West: Frequency: $0.75 \mathrm{~Hz}$

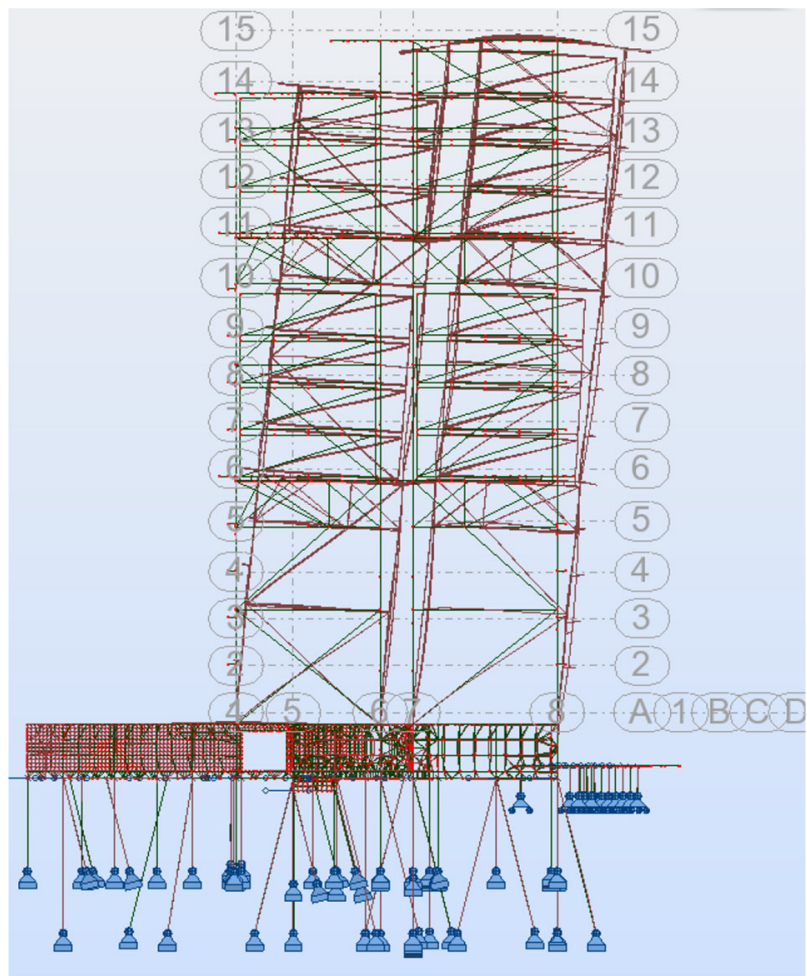

Fig. 20 Mode 2 North-South: Frequency: $0.89 \mathrm{~Hz}$ where $\mu(y, z)=$ mass per square meter. Robot Structural Analysis Professional (2013) has the ability to calculate mass-normalized mode shapes. This means that the modal mass, the numerator in Eq. (10), is set equal to 1.0, and only the integrated square of the mode shape has to be evaluated.

The nodes used to calculate the mode shape were picked from the top and bottom of each level of modules and not from the truss frame. This is believed to give a more representative equivalent mass for determination of the accelerations of the modules

The basis wind velocity in Bergen is $26 \mathrm{~m} / \mathrm{s}$ for a mean return period of 50 years. The characteristic wind velocity on site, $V_{m}$, was calculated for a return period of 1 year according to CEN 1991-1-4 (2002) and hence estimated to $19.1 \mathrm{~m} / \mathrm{s}$.

From the results of the module testing the equivalent viscous damping ratio was estimated to approximately $3 \%$ for the modules. The modules are much stiffer and have considerably higher fundamental frequencies than the overall structural system of the building so their damping properties turned out to be of minor significance to the overall behaviour. Based on the previous consideration an overall equivalent viscous damping ratio of $1.9 \%$ was chosen for the global analysis, which is within the range given for timber bridges stated in CEN 1991-1-4 (2002).

The wind-induced peak accelerations for mode 1 and 2 were calculated based on Annex C in CEN 1991-1-4 (2002). The resulting peak accelerations were determined to 0.048 and $0.051 \mathrm{~m} / \mathrm{s}^{2}$, respectively, at roof level for wind with one-year return period. By using Eq. (8), the windinduced peak acceleration on each floor could be found. This was done by using the amplitude of the mode shape in each floor, and the results are presented in Table 3. The vertical section shown in Fig. 3 identifies the vertical levels of the building.

Figure 21 shows the calculated wind-induced peak acceleration at the 13th floor for wind with one-year return period. The accelerations are plotted with small dots and compared to the evaluation curves of Figure D.1 given in ISO 10137 (2007).

\subsection{Static effect of wind}

The static response of maximum wind exposure is evaluated in the ultimate limit state. Note that the design wind load is regarded as an instantaneous load according to the Norwegian annex to Eurocode 5 (CEN 1995 2004).

Typical pattern of displacements of the glulam truss are visualized in Fig. 22. The maximum horizontal deflection at the top of the building is $71 \mathrm{~mm}$, which equals L/634 where $\mathrm{L}$ is the characteristic height of the building. The 
Table 3 Peak acceleration at each floor

\begin{tabular}{|c|c|c|c|c|c|}
\hline \multirow[t]{2}{*}{ Floor } & \multirow{2}{*}{$\begin{array}{l}\text { Height } \\
\text { (m) }\end{array}$} & \multicolumn{2}{|c|}{ East-West } & \multicolumn{2}{|c|}{ North-South } \\
\hline & & $\begin{array}{l}\text { Norm. } \\
\text { mode } \\
\text { shape }\end{array}$ & $\begin{array}{l}\text { Accele- } \\
\text { ration } \\
\left(\mathrm{m} / \mathrm{s}^{2}\right)\end{array}$ & $\begin{array}{l}\text { Norm. } \\
\text { mode } \\
\text { shape }\end{array}$ & $\begin{array}{l}\text { Accele- } \\
\text { ration } \\
\left(\mathrm{m} / \mathrm{s}^{2}\right)\end{array}$ \\
\hline \multirow[t]{2}{*}{4.} & 17.38 & 0.32 & 0.016 & 0.28 & 0.014 \\
\hline & 20.31 & 0.37 & 0.018 & 0.33 & 0.017 \\
\hline \multirow[t]{2}{*}{5.} & 20.62 & 0.37 & 0.018 & 0.34 & 0.017 \\
\hline & 23.28 & 0.40 & 0.019 & 0.37 & 0.019 \\
\hline \multirow[t]{2}{*}{6.} & 23.64 & 0.40 & 0.020 & 0.38 & 0.019 \\
\hline & 26.30 & 0.43 & 0.021 & 0.41 & 0.021 \\
\hline \multirow[t]{2}{*}{7.} & 26.66 & 0.43 & 0.021 & 0.42 & 0.021 \\
\hline & 29.32 & 0.45 & 0.022 & 0.45 & 0.023 \\
\hline \multirow[t]{3}{*}{8.} & 29.68 & 0.46 & 0.022 & 0.45 & 0.023 \\
\hline & 32.34 & 0.47 & 0.023 & 0.48 & 0.024 \\
\hline & 32.59 & 0.67 & 0.032 & 0.65 & 0.033 \\
\hline \multirow[t]{2}{*}{9.} & 33.02 & 0.68 & 0.033 & 0.66 & 0.033 \\
\hline & 35.96 & 0.73 & 0.035 & 0.72 & 0.036 \\
\hline \multirow[t]{2}{*}{10.} & 36.27 & 0.73 & 0.035 & 0.72 & 0.037 \\
\hline & 38.93 & 0.79 & 0.038 & 0.78 & 0.040 \\
\hline \multirow[t]{2}{*}{11.} & 39.29 & 0.79 & 0.038 & 0.79 & 0.040 \\
\hline & 41.95 & 0.83 & 0.040 & 0.84 & 0.043 \\
\hline \multirow[t]{2}{*}{12.} & 42.31 & 0.84 & 0.041 & 0.84 & 0.043 \\
\hline & 44.97 & 0.87 & 0.042 & 0.89 & 0.045 \\
\hline \multirow[t]{2}{*}{13.} & 45.33 & 0.87 & 0.042 & 0.90 & 0.046 \\
\hline & 47.99 & 0.89 & 0.043 & 0.94 & 0.048 \\
\hline Roof & 48.67 & 1.00 & 0.048 & 1.00 & 0.051 \\
\hline
\end{tabular}

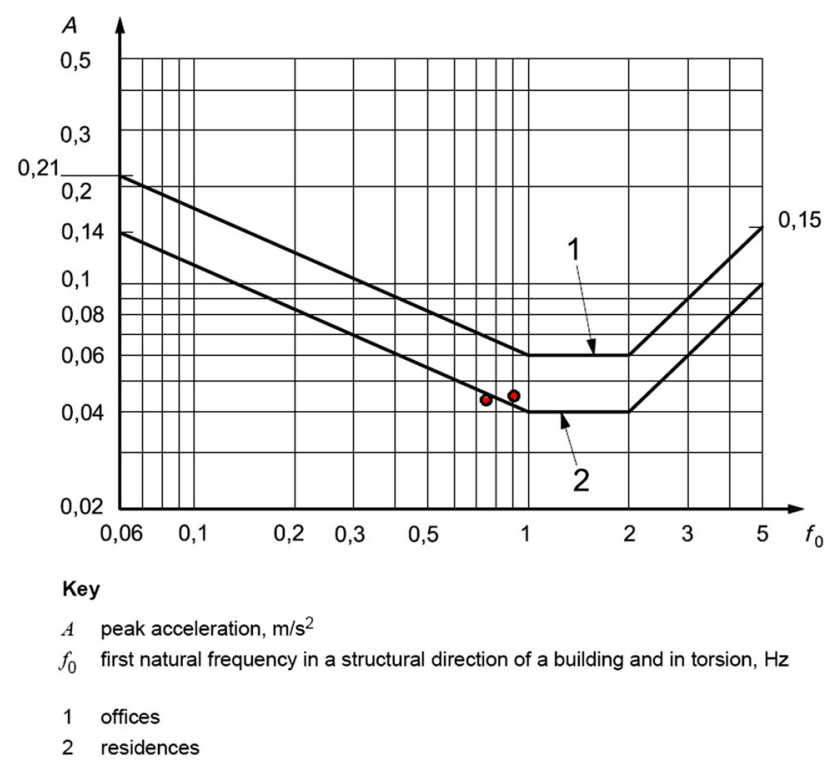

Fig. 21 Peak accelerations on the 13th Floor

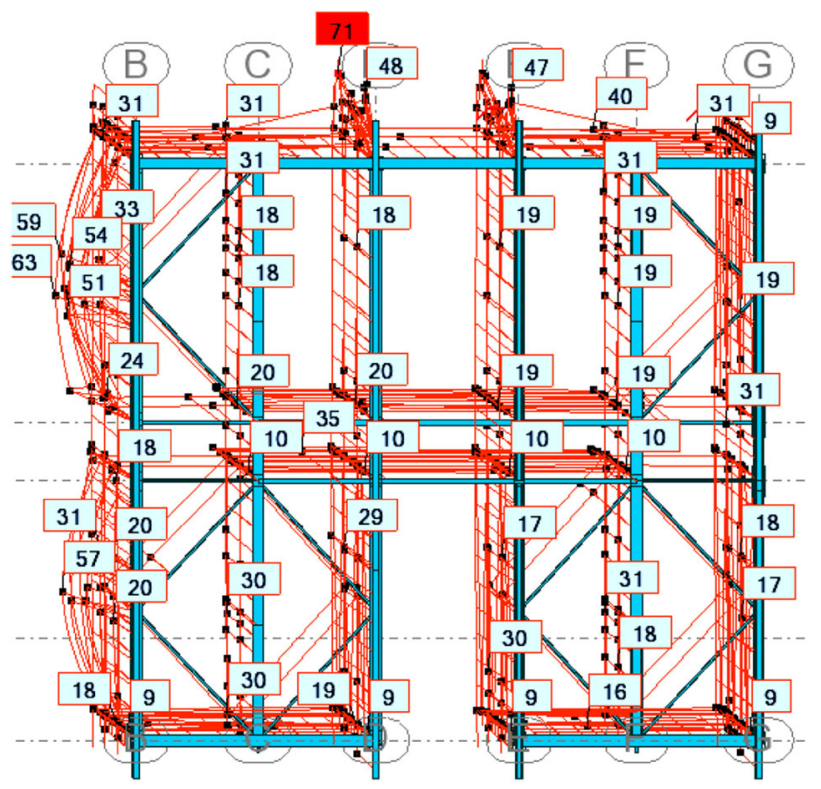

Fig. 22 Global horizontal deformations with maximum values given in the attached boxes (in $\mathrm{mm}$ ). View upwards and wind from southeast

requirement usually applied to this type of building in the design codes is $\mathrm{L} / 500$.

\section{Conclusion}

The chosen structural solution for "Treet" using glulam truss works and stacked prefabricated building modules gives a robust design. The structural effects of stacks of pre-fabricated modules installed and fastened solely to floor-slabs at multiple levels do not lead to problematic dynamical properties, as the module stacks behave as rigid bodies in the glulam truss works. There is a theoretical clearance of $34 \mathrm{~mm}$ between the building modules and the glulam trusses. This is enough to ensure necessary building tolerances, and to avoid that possible differential horizontal movement of modules and trusses interfere and inflict damage on the modules due to interface forces.

The calculated maximum acceleration for "Treet" for mode 2 at the 13th floor is slightly higher than the recommended value given in ISO 10137 (2007), but this is considered acceptable. The 12th floor will have accelerations below the recommended value. In Boggs (1995), the acceleration limit for nausea is given as $0.098 \mathrm{~m} / \mathrm{s}^{2}$ and perception limit as $0.049 \mathrm{~m} / \mathrm{s}^{2}$ for approximately $50 \%$ of the population. The perception limit for approximately $2 \%$ 
of the population is $0.020 \mathrm{~m} / \mathrm{s}^{2}$. Based on this information some of the residents in the top floors might in rare cases feel vibrations, but it is unlikely that they will become uncomfortable. The chosen structural solution for "Treet" using glulam truss works and stacked prefabricated building modules gives insignificant vibrational effects caused by wind exposure.

\section{Need for future research}

After the building is finished it is planned to install accelerometers and anemometers (to measure wind velocity) at different levels of the building. In this way it will be possible to measure the actual accelerations and damping of the building at different wind velocities. A few timber buildings have already been measured, but still the data basis is too sparse. Improved knowledge of damping properties as well as general structural behaviour of this class of buildings is of vital importance for evaluations of comfort properties. The need for this type of knowledge is clearly demonstrated herein as the numbers used in the present evaluation is basically estimations.

Furthermore, it is clear that multi-storey buildings require longer fire resistance than the $60 \mathrm{~min}$ which is covered by the current European regulations (CEN 1995-12 2004), and hopefully the next generation of Eurocodes will extend the covered range based on current and future research.

Acknowledgments The building owner is BOB, Bergen og Omegn Boligbyggelag, a Norwegian housing association and a major residential player in Bergen. Moelven Limtre is the largest glulam manufacturer in Norway and delivered and installed the glulam and CLT. The Estonian company Kodumaja delivered the prefabricated building modules that comprise the apartments. The architect for the project was the Bergen-based company Artec. SWECO Norway was responsible for the technical design and the design management. The Norwegian company Skansen Consult AS was independent third party reviewer for the fire design. The Norwegian engineering company Norconsult was independent third party reviewer for the structural design. All participants have been active in the development of the project and have together made this project possible. NTNU has been involved in the structural design issues and performed the dynamical evaluations of the residential modules and had support from The Research Council of Norway (208052), The Association of Norwegian Glulam Producers, Skogtiltaksfondet and Norwegian Public Road Administration. The support is gratefully acknowledged. Furthermore, several MSc students at NTNU have made their MSc thesis on topics related to development of tall timber buildings, and especially Anders Jørstad and Ingunn Utne have made significant contribution to this project. The article was written within the COST action FP1004 entitled Enhance mechanical properties of timber, engineered wood products and timber structures.

Open Access This article is distributed under the terms of the Creative Commons Attribution 4.0 International License (http:// creativecommons.org/licenses/by/4.0/), which permits unrestricted use, distribution, and reproduction in any medium, provided you give appropriate credit to the original author(s) and the source, provide a link to the Creative Commons license, and indicate if changes were made.

\section{References}

Abrahamsen RB, Malo KA (2014) Structural design and assembly of "treet-A 14-storey timber residential building in Norway. WCTE 2014-World Conference on Timber Engineering, Proceedings

Bjertnæs MA, Malo KA (2014) Wind-induced motions of "treet"-A 14 -storey timber residential building in Norway. WCTE 2014World Conference on Timber Engineering, Proceedings

Boggs D (1995) Acceleration index for human comfort in tall buildings-peak or rms. Researchgate, Submitted to CTBUH Monograph chapter 13, Motion Perception Tolerance and Mitigation 1997

CEN 14080 (2013) EN 14080-2013: Timber structures-glued laminated timber and glued solid timber-Requirements. European committee for standardization, Brussels, Belgium

CEN 1990 (2002) EN 1990:2002: Eurocode-basis of structural design. European committee for standardization Brussels, Belgium

CEN 1991-1-4 (2002) EN 1991-1-4:2005+A1:2010: Eurocode 1 Actions on structures, parts 1-4: General action-wind actions. European committee for standardization, Brussels, Belgium

CEN 1991 (2002). EN 1991-1-x:2002-2006: Eurocode 1 actions on structures, parts 1 to 7. European committee for standardization, Brussels, Belgium

CEN 1995-1-2 (2004) EN 1995-1-2:2004: Design of timber structures. Part 1-2: General-structural fire design. European committee for standardization, Brussels, Belgium

CEN 1995-2 (2004) EN 1995-2:2004: Design of timber structures. Part 1-2: Bridges. European committee for standardization, Brussels, Belgium

CEN 1995 (2004) EN 1995-1-1:2004+A1:2008+A2:2014: Design of timber structures. Part 1-1: General-Common rules and rules for buildings. European committee for standardization, Brussels, Belgium

Chapman J, Reynolds T, Harris R (2012) A 30 level cross laminated timber building system and analysis of the eurocode dynamic wind loads. World Conference on Timber Engineering 2012, WCTE 2012

Ewins D (2000) Modal testing: theory, practice and application. Research Studies Press, Philadelphia

ISO 10137 (2007) Bases for design of structures-Serviceability of Buildings and Walkways against Vibrations. International Organization for standardization, Geneva, Switzerland, ISO

Jørstad A (2013) Dynamic testing and numerical modelling of residential building modules. Master thesis. Trondheim, Norway, NTNU Norwegian University of Science and Technology

Jørstad A, Malo KA (2012). Measurements of structural damping in prefabricated residential modules fabricated by Kodumaja, Estonia, NTNU Norwegian Univeristy of Science and Technology

Labonnote N, Rønnquist A, Malo KA (2013a) Experimental evaluations of material damping in timber beams of structural dimensions. Wood Sci Technol 47(5):1033-1050

Labonnote N, Rønnquist A, Malo KA (2013b) Modified hysteretic damping model applied to Timoshenko timber beams. Comput Struct 121:22-31 
Labonnote N, Rønnquist A, Malo KA (2015) Prediction of material damping in timber floors, and subsequent evaluation of structural damping. Mater Struct Materiaux et Constructions 48(6): 1965-1975

Malo KA (1999) Fatigue tests of dowel joints in timber structures. Nordic Timber Council AB, Stockholm, Sweden

Malo KA, Holmestad Å, Larsen PK (2006) Fatigue strength of dowel joints in timber structures. In: 9th World Conference on Timber Engineering 2006, WCTE 2006

Reynolds T, Harris R, Chang WS (2012) Dynamic stiffness and damping of dowel-type connections for timber structures under service conditions. In: World Conference on Timber Engineering 2012, WCTE 2012

Siem J (2014) Four dowels in a column compared to an one dowel connection. WCTE 2014-World Conference on Timber Engineering, Proceedings

Simulia (2012) ABAQUS FEA software, Abaqus Documentation. Providence Dassault Systèmes Simula Corp
Sjödin J, Enquist B, Serrano E (2006) Contact-free measurements and numerical analyses of the strain distribution in the joint area of steel-to-timber dowel joints. Holz Roh Werkst 64(6):497-506

Sjödin J, Serrano E, Enquist B (2008) An experimental and numerical study of the effect of friction in single dowel joints. Holz Roh Werkst 66(5):363-372

SP (2010) Fire safety in timber buildings. Technical guidelines for Europe. SP Technical Research Institute of Sweden, Stockholm, Sweden

Spycher M, Schwarze FWMR, Steiger R (2008) Assessment of resonance wood quality by comparing its physical and histological properties. Wood Sci Technol 42(4):325-342

Utne I (2012) Numerical models for dynamic properties of a 14 storey timber building. Master Thesis. NTNU Norwegian University of Science and Technology, Trondheim, Norway

Van Overschee P, De More B (1996) Subspace identification for linear systems. Kluwer Academic Publishers, Dordrecht 